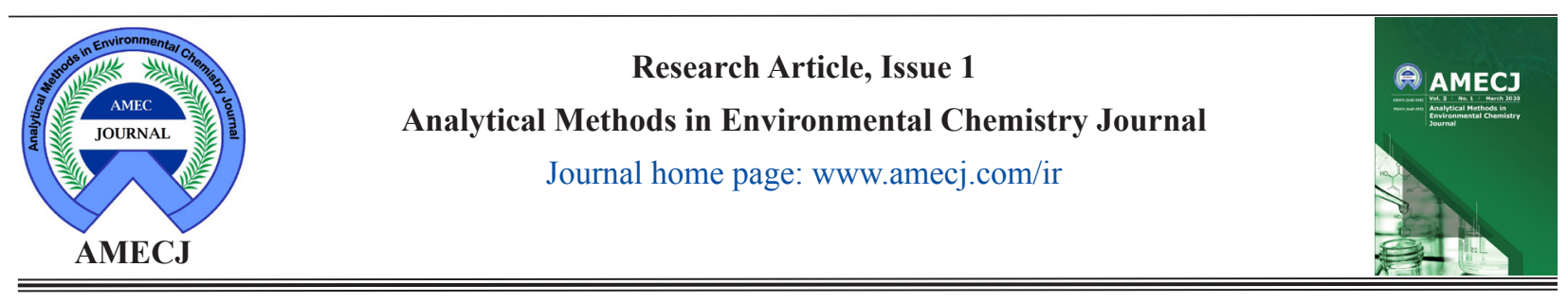

\title{
Combination of reduction with metallic sodium and adsorption with mesoporous materials for re-refining of used insulating oil via experimental design
}

\author{
Amir Vahid ${ }^{a, *}$ and Masoud Sohrab ${ }^{b}$ \\ ${ }_{a,{ }^{*}}$ Research Institute of Petroleum Industry (RIPI), West Entrance Blvd., Olympic Village, Tehran, 14857-33111, Iran
}

\begin{abstract}
A B S T RA C T
In this study, re-refining of used insulating oil by mesoporous silicate material (MCM-41) and metallic sodium was investigated. Also, the effect of silicate absorbents which was synthesized and functionalized with aluminum (Al-MCM-41) was studied (18 wt $\%$ and $36 \mathrm{wt} \%)$. The physical and structural properties of Al-MCM-41 were characterized by FT-IR, BET, XRD, FESEM and the obtained results illustrated a successful synthesis of the mesoporous material. The refined oil was treated by MCM41 adsorbent. After that, total acid number (TAN) of used insulating oil was effectively reduced by metallic sodium. The effect of some parameters such as contact time, temperature and the dosage (sodium and adsorbent to oil ratio) was designed and optimized by response surface method (RSM). The results showed that the acid number incredibly decreased at $150,60 \mathrm{~min}$ and $2 \%$ of sodium to oil. The color of the re-refined oil was significantly reduced. The factors such as, time, temperature and dosage was statistically studied by ANOVA. The adsorption of MCM-41 was also studied by this way. Based on proposed procedure, the modeling was carried out. Treating of oil with MCM-41 after using metallic sodium causes lower color of oil.
\end{abstract}

\section{Introduction}

Used oils are the important contaminates of ecosystems which leads to water and soil pollution [1]. In other hands, the used oil is to provide a source of valuable base oil [2]. The oil has duties such as lubricating moving parts of engine, reducing friction, cooling agent, act as an anti-corrosion, protecting, against wear, act as an cleaning agent, conducting force and removing contaminates [3]. Some additives added to the oil to enhance its

*Corresponding Author. Amir Vahid

E-mail: avahid753@gmail.com

https://doi.org/10.24200/amecj.v3.i01.74 application for a specific task. These additives are almost hazardous materials for environment. The insulating (transformer) oil degradation under working condition of high voltage transformers occurs mainly due to oxidation and thermal decomposition at high temperatures after long period of using [4]. These oxidation products of used insulating oil contain carboxylic acids, ketones and alcohols, which then condense to from polymeric materials [5]. The oxidation of products caused to metal corrosion, viscosity increase, sludge and varnish formation [6]. The acidity of used oil is depended to oxidation of products [7]. Sodium 
is a reactive metal which is easily oxidized. It has a powerful affinity for certain oxidative organic species. The rate of reaction depends on the metaloil interface. The rate of reaction between the solid metal and the oxidation of oil products depends on the extent of this interface. Sodium dispersions as resemble emulsions having a high metal surface area. The dispersion is used at a temperature which is above that of the melting point of the sodium $\left(98^{\circ} \mathrm{C}\right)$. In this way a reasonable reaction rate can be achieved [8]. The reaction of sodium with oxidation products such as acid carbocyclic caused to obtain the solid and hydrogen as below equation 1 . The reaction between sodium with ketones caused to reduce ketones and obtained tertiary alcohol. Also, the reaction of sodium with alcohols produced the solid and hydrogen (Eq. 2).

\section{$2 \mathrm{CH}_{3} \mathrm{COOH}+2 \mathrm{Na} \rightarrow 2 \mathrm{CH}_{3} \mathrm{COONa}+\mathrm{H}_{2} \quad$ (Eq. 1)}

$2 \mathrm{CH}_{3} \mathrm{OH}+2 \mathrm{Na} \rightarrow 2 \mathrm{CH}_{3} \mathrm{ONa}+\mathrm{H}_{2}$

Recycling of used oil is very important as less energy and cost compared to refining of crude oil.

Recycling of used oil helps to air, soil and water pollutions in the environment. Many sorbent were used for recycling of used oil as oxidation and refining of oil products. The various treatments were used for improving used oil by acid-clay process, solvent extraction, vacuum distillation and hydrogenation methods. These are high technology which combines a few generic methods in its process. Due to the hard recycling of used oil, the single method cannot be generated a standard emission controlled process. So, for specific processes of recycling waste oils, sophisticated equipment was used. KTI and STP methods combine the vacuum distillation and hydrofinishing together. By the STP method, dehydration, vacuum distillation, separation of the lubricating fraction and hydrofinishing were used [9-17]. In this paper, the MCM-41 was used for collecting product. By heating oil, the oxidation products and absorption of new oxidation products had created. For determination of constituent's acid number oil, the titration of alcoholic base method was used [18]. For determination of discoloration (reduce oxidation products) and new oxidation products, the spectrophotometer with wavelength of $419 \mathrm{~nm}$ and $312 \mathrm{~nm}$ was used.

\section{Experimental}

\subsection{Reagent and Materials}

The cetyltrimethyl ammonium bromide (CTAB), sodium silicate $\left(\mathrm{Na}_{2} \mathrm{SiO}_{3}\right)$, polyethylene glycol 4000(PEG4000), ethanol, aluminum nitrate, acetic acid, sodium hydroxide ( $\mathrm{NaOH}), \mathrm{TAN}, 2$-propanol, toluene, p-naphtholbenzein, potassium hydroxide, and deionized water (DW) was purchased from Merck, Germany and used for all synthesis and TAN method.

\subsection{Synthesis of MCM-41}

For synthesis of MCM-41, $180 \mathrm{~g}$ of DW and 3.7 $\mathrm{g}$ of CTAB mixed at room temperature and then $11.1 \mathrm{~g}$ of ethanol was added to suspension until receive colorless position and then, $11.1 \mathrm{~g}$ sodium silicate as silicate source, $0.6 \mathrm{~g}$ PEG4000 was used. The acid acetic 0.1 molar was used for fixing $\mathrm{PH}$ near 9.5. The mixture was stirrer at room temperature for $48 \mathrm{~h}$ and then, put it awayfor $1 \mathrm{~h}$. The precipitate product was filtered and washed by mixture of ethanol / DW (1:5 ratio) and dry at room temperature for $24 \mathrm{~h}$. Finally, the solid cavities put in electric furnace for $6 \mathrm{~h}$ at high temperature up to $550^{\circ} \mathrm{C}$ (calcination process) [19].

\subsection{Synthesis of Al-MCM-41}

The synthesis of Al-MCM-41 method is similar to the synthesis of MCM-41method. For the synthesis of Al-MCM-41 method, the aluminum nitrate (Aluminum source) was added to suspension and then sodium silicate. For fixing $\mathrm{PH}$, the $\mathrm{NaOH}$ (0.1molar) was used for reducing acidic PH [20].

\subsection{Characterization Method}

The X-ray diffraction (XRD) patterns recorded on seritef XRD 300 PTS. The X-ray diffractometer using cu k $\alpha$ radition $(\lambda=1.54)$ and scan rate 0.02 $20 / \mathrm{S}$ at room temperature was used. Nitrogen 
adsorption-desorption isotherms for mesoporous (BET) recorded on BELSORP-miniII. Fourier transform infrared spectroscopy (FT-IR) recorded to $4000-400 \mathrm{~cm}^{-1}$ area on a Thermo Nicolet Nexus 870. Scanning electron micros copy (SEM) images obtained on Tescan Mira3Xmu.

\subsection{Total Acid Number (TAN)}

For determining of acid, $2 \mathrm{~g}$ of sample added to 20-30 $\mathrm{mL}$ of solvent and then the sample dissolved completely in solvent (solvent: $100 \mathrm{~mL}$ toluene, 99 $\mathrm{mL}$ isopropanol and $1 \mathrm{~mL} \mathrm{DW}$ ) and the resulting single-phases solution was titrated at room temperature with standard alcoholic base (solution Hydroxide potassium 0.1 molar). Finally, the end point indicated to changing color by adding 0.5 $\mathrm{mL}$ of p-naphtholbenzien solution (orange to green/ green-brown)[18].

\subsection{Refining used oil by MCM-41 and silicate -} Aluminums

The absorbent and acid (0.15) diluted with Heptane (1:9, $1 \mathrm{~mL}$ Oil $+9 \mathrm{~mL}$ Heptane) was added to used insulating oils and the refining was determined at $419 \mathrm{~nm}$ area. First, $20 \mathrm{~mL}$ of used insulating oils was poured in container 1 with amount of 0.2 g MCM-41, container 2 with amount of 0.2 ALMCM-41 (18wt\%) and container 3 with amount of $0.2 \mathrm{~g}$ of Al-MCM-41 (36wt\%). In order to favorite contact between adsorbent and used insulating oils, the mixture was shacked for $15 \mathrm{~min}$ and then the sorbent separated $t$ from used insulating oils by centrifuging process.

\subsection{The experiment of sodium with used oil}

The refining of used oil based on acid number 0.15 which was diluted with Heptane 1:9 (1:9, $1 \mathrm{~mL}$ Oil $+9 \mathrm{~mL}$ Heptane) and absorbent 2.436, was determined at $419 \mathrm{~nm}$ area.. $20 \mathrm{~mL}$ of used oil was poured in two containers. The amount of $0.2 \mathrm{~g}$ sodium metallic poured in container 1 and shacked based on magnet stirrer for interaction with used oil at room temperature (1 hour). In container 2 , we increased temperature up to $100^{\circ} \mathrm{C}$ and then 0.2 $\mathrm{g}$ of sodium metallic was added to used insulating oils in present of magnet stirrer for $1 \mathrm{~h}$.

\subsection{The experiment of sodium with used oil and refining by absorbents}

The effect of sodium with used oil and refining by absorbents MCM-41, Al-MCM-41 were investigated before and after use of sodium metallic. The used oil contains acid number 0.26 that diluted with Heptane 1:9 (1mL Oil $+9 \mathrm{~mL}$ Heptane) that contain absorbent 2.794, $419 \mathrm{~nm}$ area. In first steps, each absorbent was used based on refining method at room temperature and then used sodium metallic added at $100^{\circ} \mathrm{C}$. In second steps, we used sodium metallic at $100^{\circ} \mathrm{C}$ and next used absorbent at room temperature.

\subsection{Optimized effective factors on acid number reduction}

In this research, the effective parameters and their interaction (acid reduction and oil color reduction) were studied and optimized by RSM method. Finally, a model in which could explain influence effective parameters on reactions and interaction between them. Three parameters predict on influence factors on acid number reduction and color oil reduction were obtained by sodium metallic dosage, sodium metallic contact time and temperature. So, this design based on BBD method was used for experimental which could obtained more information about influence parameters of measurement. According to Design-Expert v7 software 17, the experimental was designed for metallic sodium and refining absorbent MCM41 (Table 1). The experimental design of used insulating oils contained 0.09 acid numbers based on heptane diluted 1:9 ratios (1 cc oil $+9 \mathrm{cc}$ heptane) and absorbent 4.818 in $3.12 \mathrm{~nm}$ to area.

\section{Results and Discussions}

\subsection{FT-IR Spectrums}

The spectrums of FT-IR were shown in figures of 1, 2 and 3. The Waveland of $816 \mathrm{~cm}^{-1}$ and 1050 $\mathrm{cm}^{-1}$ related to $\mathrm{Si}-\mathrm{O}-\mathrm{Si}$ bonds vibration in MCM41 structure. The bands in $1050 \mathrm{~cm}^{-1}$ related to stretching vibration asymmetric $\mathrm{Si}-\mathrm{O}-\mathrm{Si}$ and related 
Table 1. The design of experiment parameters

\begin{tabular}{lccc}
\hline experiments & Contact time(min) & Tamperature $\left({ }^{\circ} \mathbf{C}\right)$ & Dosege $\%$ \\
\hline 1 & 60 & 100 & 2 \\
2 & 180 & 100 & 2 \\
3 & 60 & 150 & 2 \\
4 & 180 & 150 & 2 \\
5 & 60 & 100 & 6 \\
6 & 180 & 100 & 6 \\
7 & 60 & 150 & 6 \\
8 & 180 & 150 & 6 \\
9 & 39 & 125 & 4 \\
10 & 201 & 125 & 4 \\
11 & 120 & 91 & 4 \\
12 & 120 & 159 & 4 \\
13 & 120 & 125 & 1.29 \\
14 & 120 & 125 & 6.71 \\
15 & 120 & 125 & 4 \\
16 & 120 & 125 & 4 \\
17 & 120 & 125 & 4 \\
\hline
\end{tabular}

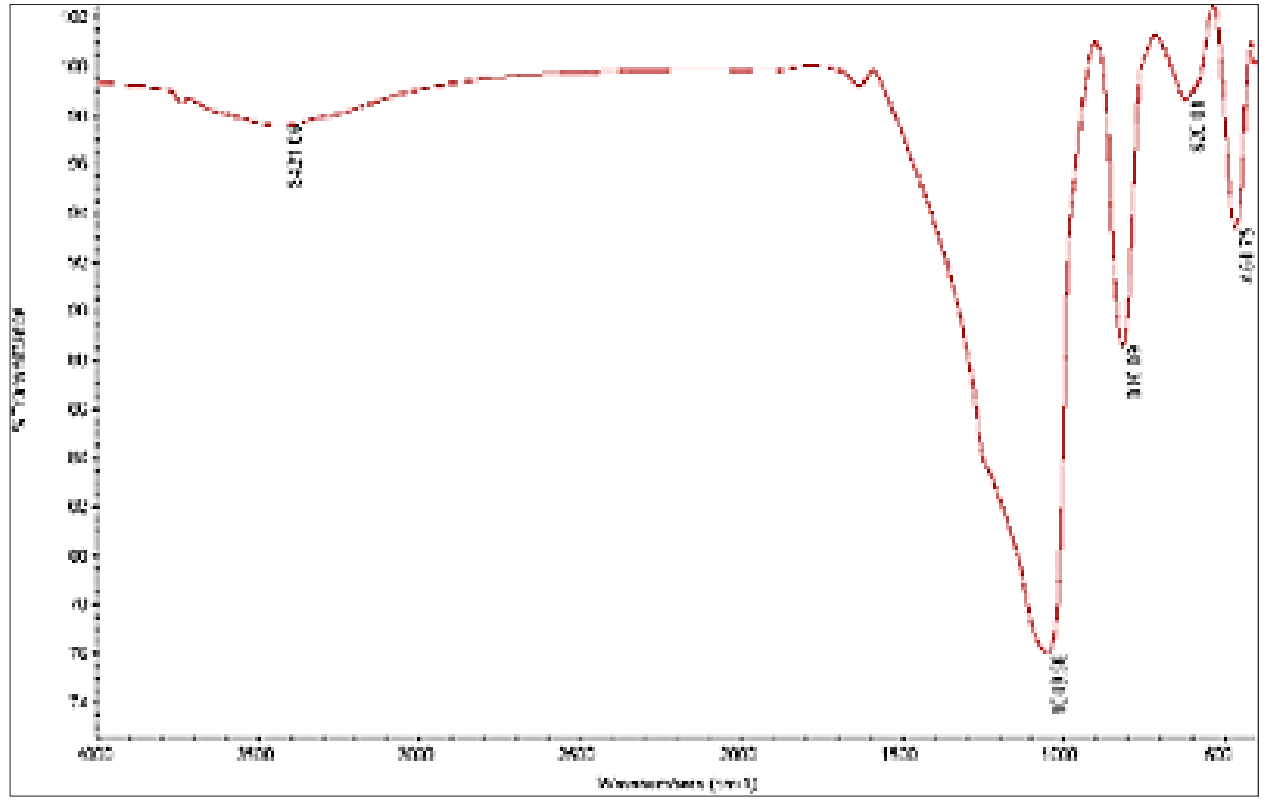

Fig. 1. The FT-IR of MCM-41

to stretching vibration symmetric

$\mathrm{Si}-\mathrm{O}-\mathrm{Si}$ and $465 \mathrm{~cm}^{-1}$ is related to angular vibration Si-O-Si. The bands of $3421 \mathrm{~cm}^{-1}$ and $1690 \mathrm{~cm}^{-1}$ related to vibration of sinanol hydroxide group that is the reason of adsorbent water molecules which was shown in figure 2, 3. Based on figures, the amount of metal and polarity structure was increased [21, 22].

\subsection{XRD analysis}

According to XRD pattern especially diffraction of XRD $d_{100}$ spacing in low angele $2 \theta$ region, the confirm mesoporous structure and hexagonal lattice [23]. Well resolver sharp peaks at higher order diffractions imply that long range order present in this sample (Fig. 4). 


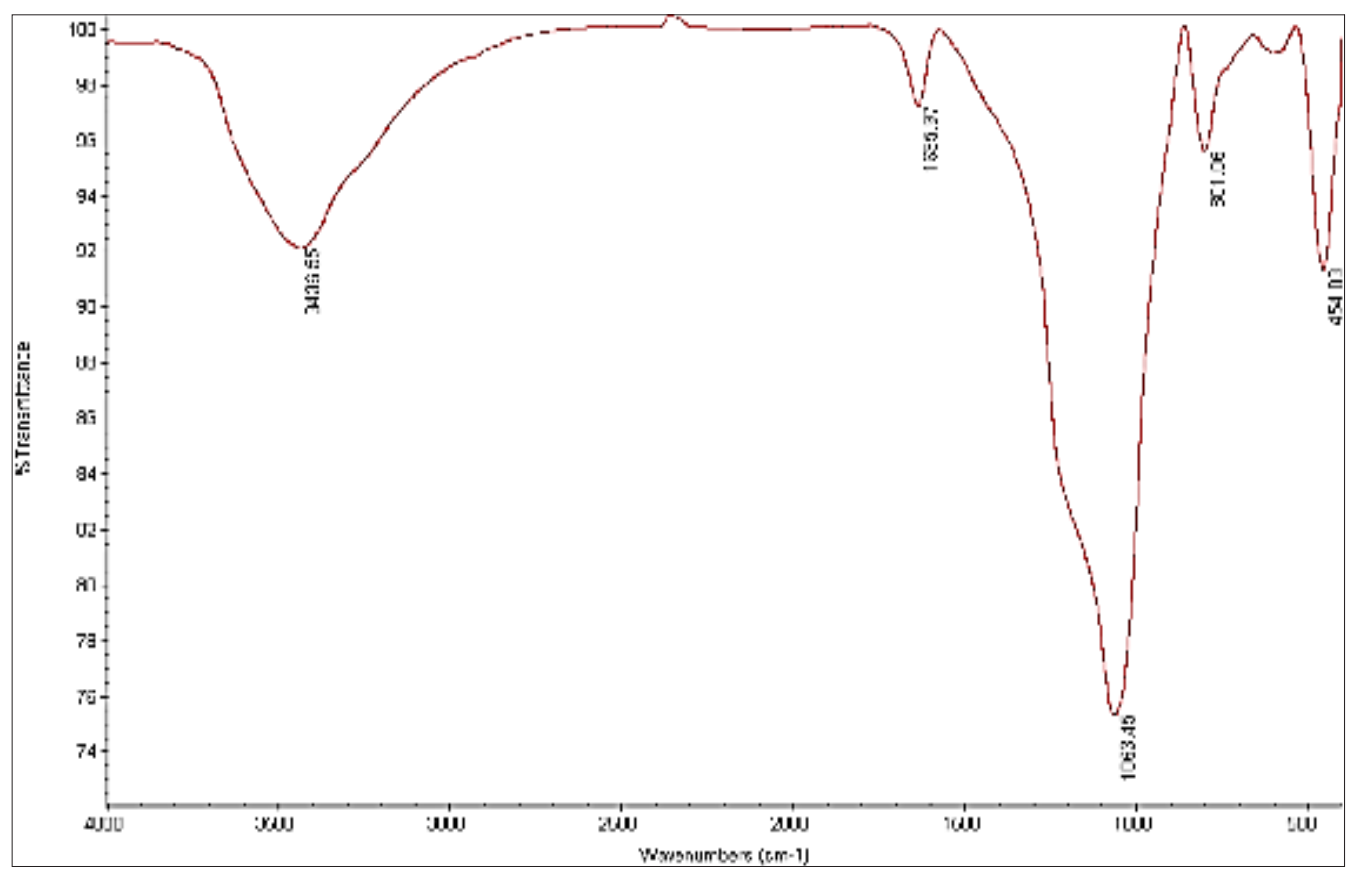

Fig. 2. The FT-IR of $18 \%$ wtAl-MCM-41

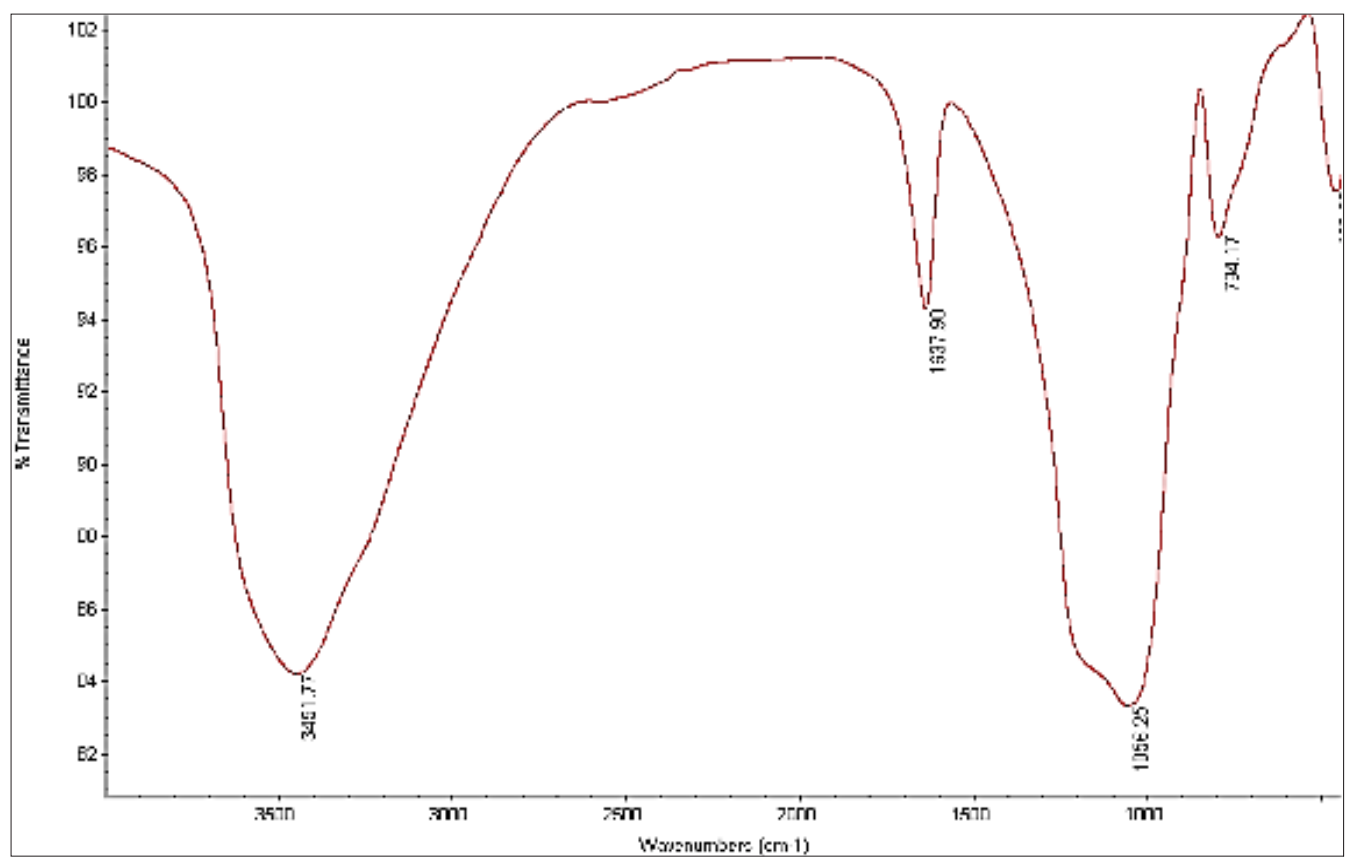

Fig. 3. The FT-IR of $36 \%$ wt Al-MCM-4

\subsection{BET analysis}

Nitrogen adsorption-desorption of MCM-41 and $36 \%$ wt Al-MCM-41 showed that the mesoporous MCM-41 had pore diameter more $3 \mathrm{~nm}$ and specific surface area about $919.65 \mathrm{~m}^{2} \mathrm{~g}^{-1}$. Mesoporous functionlized with aluminium $36 \% \mathrm{wt}(\mathrm{Al}-$ MCM-41) have been pore diameter of aout 2.6 $\mathrm{nm}$ and specific surface area about $526.92 \mathrm{~m}^{2} \mathrm{~g}^{-1}$. Decrease of surface area is due to the grafting of alluminom species

\subsection{FESEM analysis}

Figure 5 amd 6 showed the images of FESEM for MCM-41 and structure morphology with worm- 


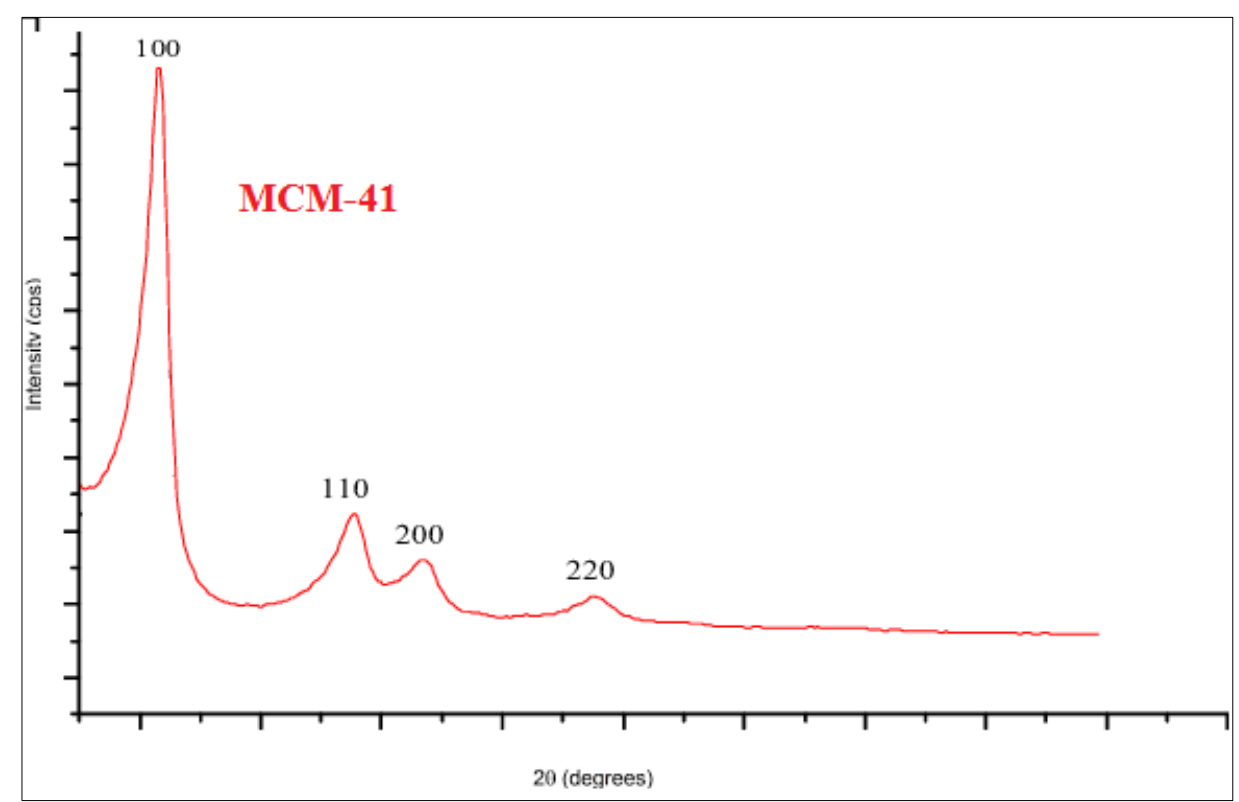

Fig. 4. The low angle of XRD patterns for MCM-41

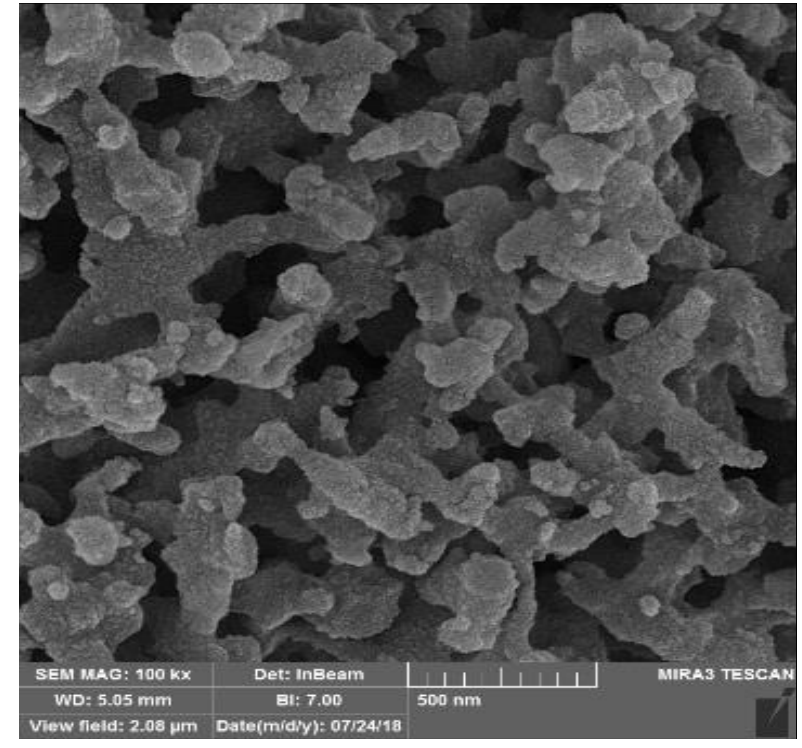

Fig. 5. The FESEM of MCM-41(200000)

like intera-particle structure. The FESEM with magnification 200000 and 100000 for MCM-41 was shown in Figure 5 and 6, respectively.

\subsection{Analyzed refining used oil with MCM-41 absorbent}

As comparing to BET analysis of Al-MCM41(36wt $\%)$, the effective surface area was more than MCM-41. In Al-MCM-41, the reaction between aluminum metal and oxidation products occurred and therefore the acid number amount more than

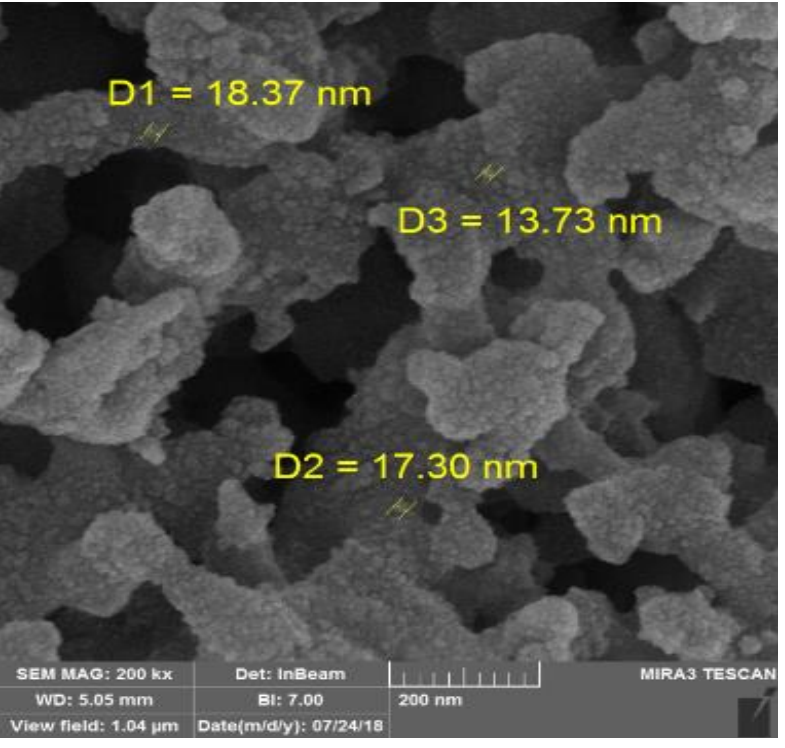

Fig. 6. The FESEM of MCM-41(100000)

used oil color decreased. The Al-MCM-41(18 $\mathrm{wt} \%$ ) has less aluminum metal as compared to AlMCM-41(36 wt \%), therefore as low aluminum amount, the less reaction between aluminum and oxidation products occurred. In other words, according to aluminum amount reduction, the effective surface will increased and therefore the amount of acid number reduce (Table 2).

As lacking metal according to BET analysis, the MCM-41 has more effective surface than two other absorbent and adsorbent oxidation products 
Table 2. .Results of refining analysis for used oil with MCM-41 and silicate rich Al

\begin{tabular}{lcc}
\hline Type of absorbent & Absorbance(419nm) & Acid number \\
\hline MCM-41 & 1.950 & 0.085 \\
18wt\%MCM-41 & 2.174 & 0.084 \\
36wt\%MCM-41 & 2.659 & 0.071 \\
\hline
\end{tabular}

therefore acid number less reduce toward two other absorbent and so oil color reduce more.

\subsection{Metallic sodium reaction}

The reduction power of metallic sodium with oxidation products at $100^{\circ} \mathrm{C}$ was appreciably higher than that of $25^{\circ} \mathrm{C}$. The melting point of metallic sodium is $98^{\circ} \mathrm{C}$ and therefore contact surface area with oil increase at $100^{\circ} \mathrm{C}$ and renewed continuously and amount of metallic sodium reaction with oxidation products increased. One of oxidation products was derivatives of carboxylic acids and carbonyl groups which reduced at this temperature. The sodium and TAN decreased by increasing sodium reaction time and temperature. The reaction between metallic sodium and oxidation products was increased and this products caused to increase the color of oil in this temperature (Table 3 ).

\subsection{Analysis of metallic sodium and refining with MCM-41 and Al-MCM-41}

The adsorbent addition and reduction based on metallic sodium is very important for re-refining process. Table 4 showed, the results of experiments at equal level of factors. The difference was depended to the order of treatment with adsorbent and reducing agent. The results showed, the first treating based on adsorbent in better quality of final re-refined insulating oil in terms of color. But the TAN process had a slightly higher.

\subsection{Optimized of effective factors acid number reduction}

According to DOE and temperature, dosage and contact time, different results were obtained and showed in Table 5. The ANOVA of he obtained results is shown in Table 6. Prob $>\mathrm{F}$ is a good measure of importance of each term in the first order model. Interaction terms are also importance although the $\mathrm{BC}$ has the lowest effect on the response of model.

The model can be mentioned in the following equation (Eq. 3) in terms of real factors. Adsorption of byproducts by mesoporous materials is investigated by DOE which was shown in Table 7. Acidity calculating (A)

(Eq. 3)

$\mathrm{A}=-0.026272105+(0.000324288 \times$ Time $)+(0.000263706$

$\times$ Temperature $)+\left(3.2824 \times 10^{-5} \times\right.$ Dosage $)-(0.00000225$

$\times$ Time $\times$ Temprature $)-\left(7.29167 \times 10^{-8} \times\right.$ Time $\times$ Dosage -

$(0.000000125 \times$ Temperature $\times$ Dosage $)$

The quadratic equation (Eq. 4) has obtained after to

Table 3. Results of treatment of used insulating oil y metallic sodium.

\begin{tabular}{lccc}
\hline Treatment & temperature & Absorbance(419nm) & Acid number \\
\hline metallic sodium & $25^{\circ} \mathrm{C}$ & 2.575 & 0.11 \\
metallic sodium & $100^{\circ} \mathrm{C}$ & 2.890 & 0.03 \\
\hline
\end{tabular}

Table 4. Analysis of metallic sodium and refining with absorbent MCM-41 and Al- MCM-

\begin{tabular}{lcc}
\hline Type of absorbent & Absorbance(419nm) & Acid number (TAN) \\
\hline Metallic sodium+MCM-41 & 2.404 & 0.045 \\
Metallic sodium+18 wt\% Al-MCM-41 & 2.678 & 0.05 \\
Metallic sodium+36 wt\% Al-MCM-41 & 3.094 & 0.05 \\
MCM-41+ Metallic sodium & 2.300 & 0.056 \\
18 wt\% Al-MCM-41+ Metallic sodium & 2.267 & 0.055 \\
36 wt\% Al-MCM-41+ Metallic sodium & 2.480 & 0.056 \\
\hline
\end{tabular}


Table 5. Experimental design data for metallic sodium and MCM-41

\begin{tabular}{lccccc}
\hline experiments & Acid number & Absorbance (312nm) & contact time (min) & Tamperatur e $\left({ }^{\circ} \mathbf{C}\right)$ & Dosege $(\%)$ \\
\hline 1 & 0.009 & 4.597 & 60 & 100 & 200 \\
2 & 0.019 & 4.655 & 180 & 100 & 200 \\
3 & 0.014 & 4.675 & 60 & 150 & 200 \\
4 & 0.011 & 4.400 & 180 & 150 & 200 \\
5 & 0.016 & 4.647 & 60 & 100 & 600 \\
6 & 0.023 & 4.659 & 180 & 150 & 600 \\
7 & 0.019 & 4.723 & 60 & 150 & 600 \\
8 & 0.014 & 4.562 & 180 & 125 & 400 \\
9 & 0.014 & 4.743 & 39 & 125 & 400 \\
10 & 0.014 & 4.760 & 201 & 1 & 400 \\
11 & 0.018 & 4.679 & 120 & 125 & 400 \\
12 & 0.019 & 4.735 & 120 & 125 & 400 \\
13 & 00.15 & 4.614 & 120 & 125 & 671 \\
14 & 0.014 & 4.477 & 120 & 125 & 400 \\
15 & 0.014 & 4.659 & 120 & 125 & 400 \\
16 & 0.014 & 4.667 & 120 & 120 & 400 \\
\hline
\end{tabular}

Table 6. Results of metallic sodium

\begin{tabular}{lccccc}
\hline Source & Sum of squares & df & Mean square & F-Value & P-Value Prob>F \\
\hline model & 0.000165 & 6 & 2.75 & 22.50 & $<0.0001$ \\
A-Time & 0.0000008 & 1 & 0.0000008 & 6.61 & 0.0278 \\
B-Temp & 0.0000023 & 1 & 0.0000023 & 18.92 & 0.0014 \\
C-Dosage & 0.0000033 & 1 & 0.0000033 & 27.27 & 0.0004 \\
AB & 0.0000911 & 1 & 0.0000911 & 74.64 & $<0.0001$ \\
AC & 0.0000061 & 1 & 0.0000061 & 5.01 & 0.0490 \\
BC & 0.0000031 & 1 & 0.0000031 & 2.55 & 0.1407 \\
Residual & 0.0000012 & 10 & 0.00000012 & - & - \\
Lack of fit & 0.0000012 & 8 & 0.00000015 & - & - \\
Pure Error & 0 & 2 & 0 & - & - \\
Cor Total & 0.00017 & 16 & - & - & - \\
\hline
\end{tabular}

Table 7. Results of adsorption of MCM-41.

\begin{tabular}{lccccc}
\hline source & Sum of squares & df & Mean square & F-Value & P-Value Prob>F \\
\hline model & 0.170 & 9 & 0.0189 & 30.8 & $<0.0001$ \\
A-Time & 0.0114 & 1 & 0.0114 & 18.59 & 0.0035 \\
B-Temp & 0.0000042 & 1 & 0.0000042 & 0.069 & 0.8003 \\
C-Dosage & 0.0053 & 1 & 0.0053 & 8.68 & 0.0215 \\
AB & 0.045 & 1 & 0.045 & 74.8 & $<0.0001$ \\
AC & 0.0035 & 1 & 0.0035 & 5.74 & 0.0476 \\
BC & 0.0081 & 1 & 0.0081 & 13.34 & 0.0081 \\
$\mathrm{~A}^{2}$ & 0.0066 & 1 & 0.0066 & 10.83 & 0.0133 \\
$\mathrm{~B}^{2}$ & 0.0067 & 1 & 0.0067 & 11.02 & 0.0128 \\
$\mathrm{C}^{2}$ & 0.082 & 1 & 0.082 & 134.7 & $<0.0001$ \\
Residual & 0.0042 & 7 & 0.00061 & - & - \\
Lack of fit & 0.0033 & 5 & 0.0066 & 1.32 & 0.48 \\
Pure Error & 0.00099 & 2 & 0.00049 & - & - \\
Cor Total & 0.174 & 16 & - & - & - \\
\hline
\end{tabular}


predict reduction of color of oil by MCM-41

Adsorption of predict reduction of color of oil by MCM-41(Ads)

(Eq. 4)

Ads $=4.801224864+(0.002992049 \times$ Time $)-$ $(0.009280222 \times$ Temprature $)+(0.001318102$

$\times$ Dosage $)-(0.0000505 \times$ Time $\times$ Temprature $)$

$+\left(1.75 \times 10^{-6} \times\right.$ Time $\times$ Dosage $)+\left(6.4 \times 10^{-6} \times\right.$

Temprature $\times$ Dosage $)+\left(8.74636 \times 10^{-6} \times\right.$ Time $\left.^{2}\right)$

$+\left(5.0816 \times 10^{-5} \times\right.$ Temprature $\left.^{2}\right)-\left(2.77655 \times 10^{-6}\right.$

$\times$ Dosage $\left.^{2}\right)$

\subsection{The effect of contact time}

The graph of effect of time on acidity at dosage (400) and temperature $\left(125^{\circ} \mathrm{C}\right)$ is linear with increasing of time, new oxidation products in oil was produced more and therefore, the acid number increased (Fig. 7).

\subsection{The effect of temperature}

The graph of temperature on acidity is linear which was shown in Figure 8. By increasing of temperature amount of acid number reduced and at $150^{\circ} \mathrm{C}$ the lowest acid number obtained. By increasing of temperature, the metallic sodium change to liquid an also viscosity of oil significantly reduced, because of its low viscosity index. As a result, the surface was expanded when the temperature, diffusion of oil and the surface of sodium particles increased. Therefore, the amount of metallic sodium with oxidation products as carboxylic acid has more reaction and caused to reduce TAN.

\subsection{The effective of metallic sodium dosage}

Figure 9 showed that the graph of dosage on acidity at temperature $125^{\circ} \mathrm{C}$ and contact time $120 \mathrm{~min}$.

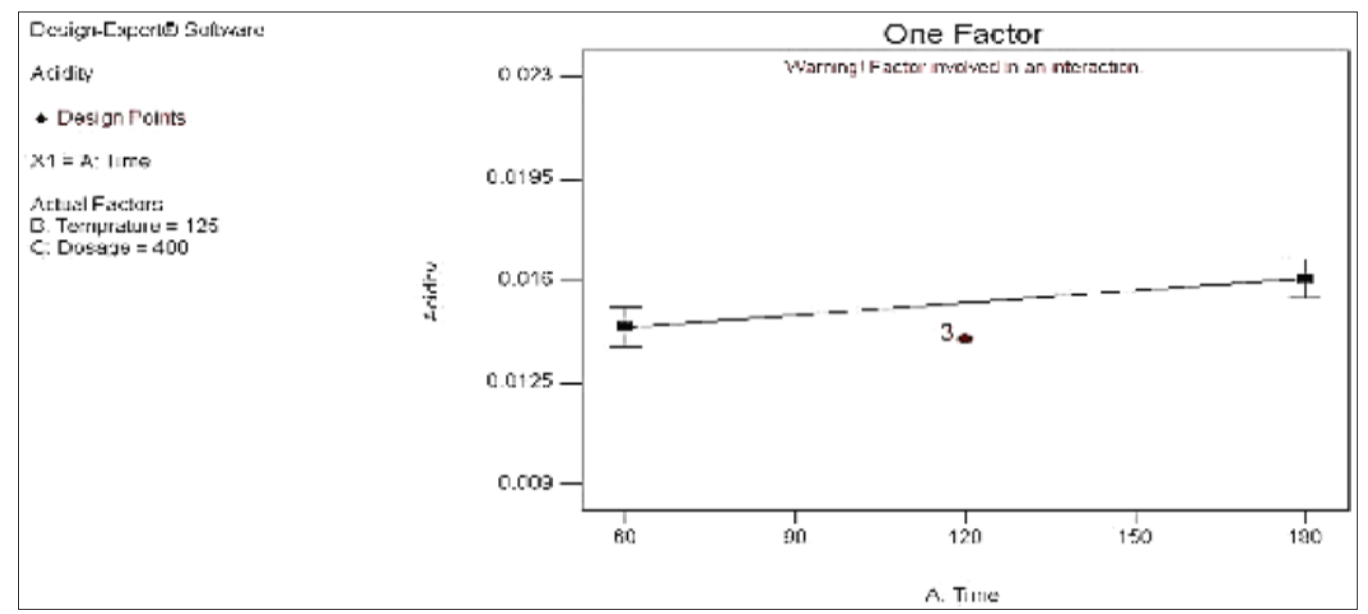

Fig. 7. The effect of metallic sodium contact time on TAN.

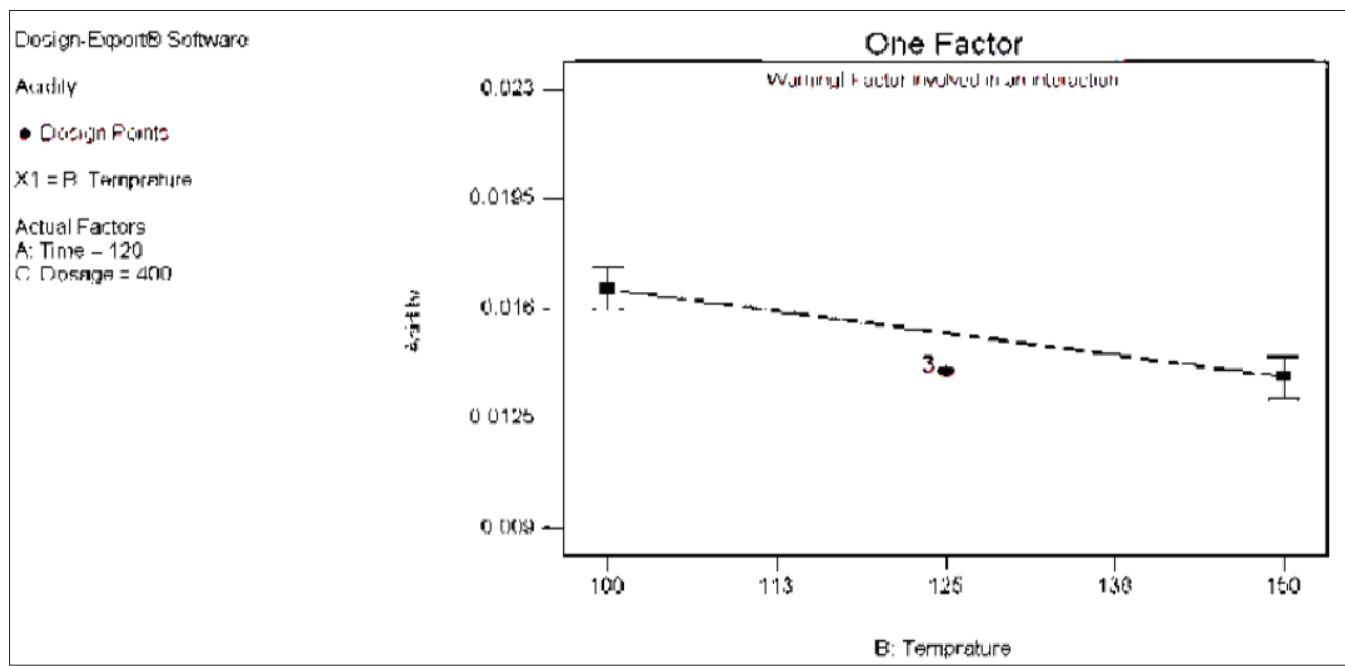

Fig. 8. The effect of metallic sodium reaction temperature on TAN 
The linear graph is clear. By increasing of metallic sodium, the higher amount of acid number in dosage $600 \%$ was observed. Therefore, by increasing of metallic sodium, the more reaction between sodium and oxidation products as in carboxylic acid was happened.

\subsection{The effect of contact time on color of oil by MCM-41}

Based on Figure 10, the graph of time factor on oil color at temperature $\left(125^{\circ} \mathrm{C}\right)$ and contact dosage (400) was constant. At $120 \mathrm{~min}$, the color reduction was observed and after higher time, the color slightly increasing.

\subsection{The effect of reaction temperature on oil color}

As can be seen in the curvature in Figure 11 until temperature $125^{\circ} \mathrm{C}$, discoloration was occurred. After $125^{\circ} \mathrm{C}$, the color was increased with slow slop.

\subsection{The effect of dosage on oil color by MCM-41}

Figure 12 showed, the graph of dosage factor (metallic sodium ratio to oil ) on color of oil in time $(125 \mathrm{~min})$ and temperature $\left(125^{\circ} \mathrm{C}\right)$ was linear. Based on the curvature, the color increased up to 400 dosages and after it the color decreases.

The Figures 13, 14 and 15 displayed the interaction

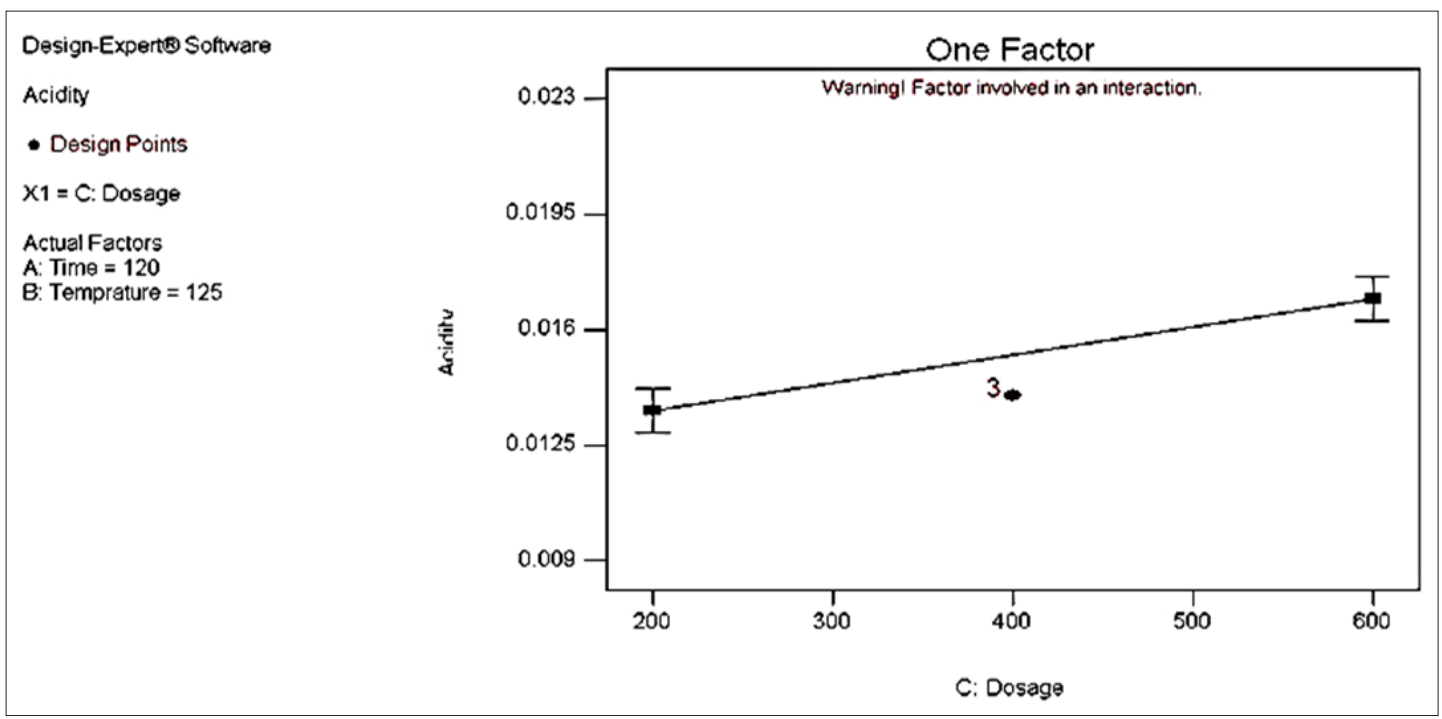

Fig. 9. The effect of metallic sodium dosage factor (sodium to oil ratio) on TAN

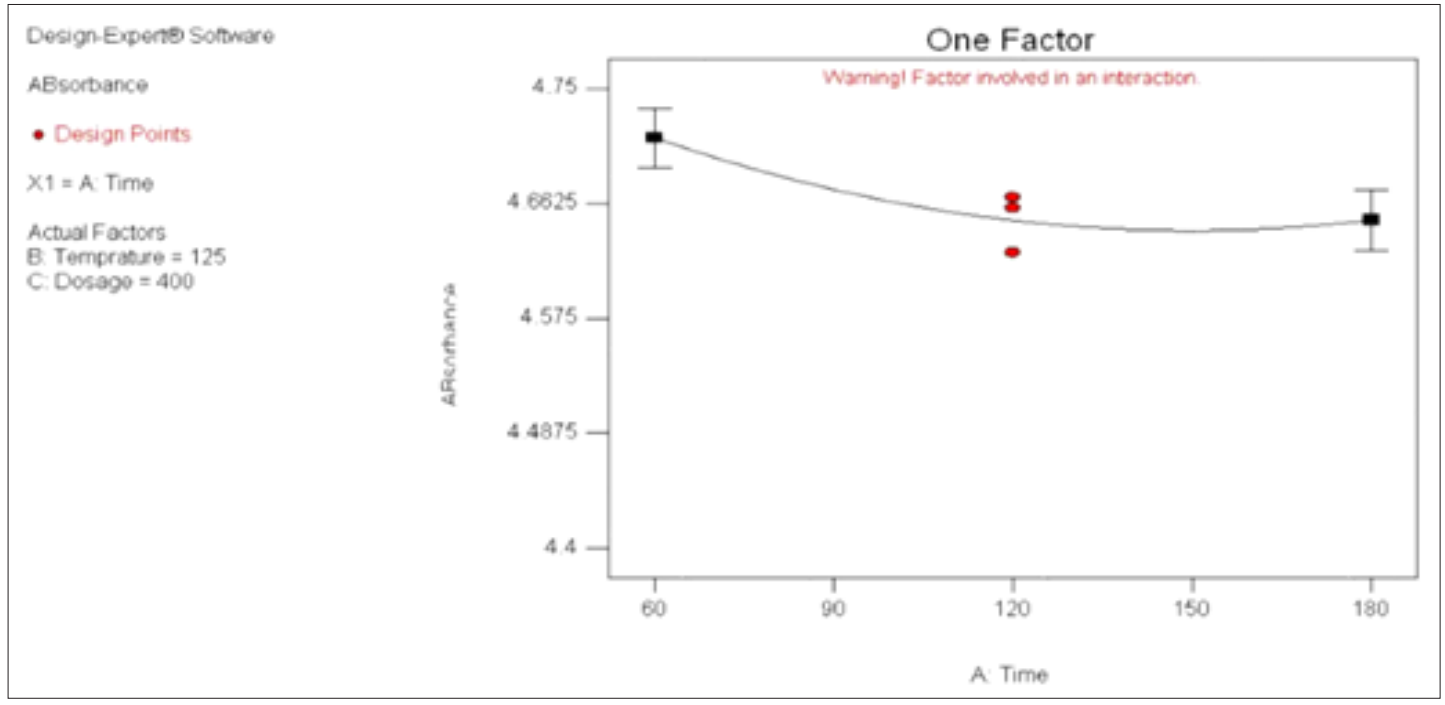

Fig. 10. The effect of contact time on oil color by MCM-41 


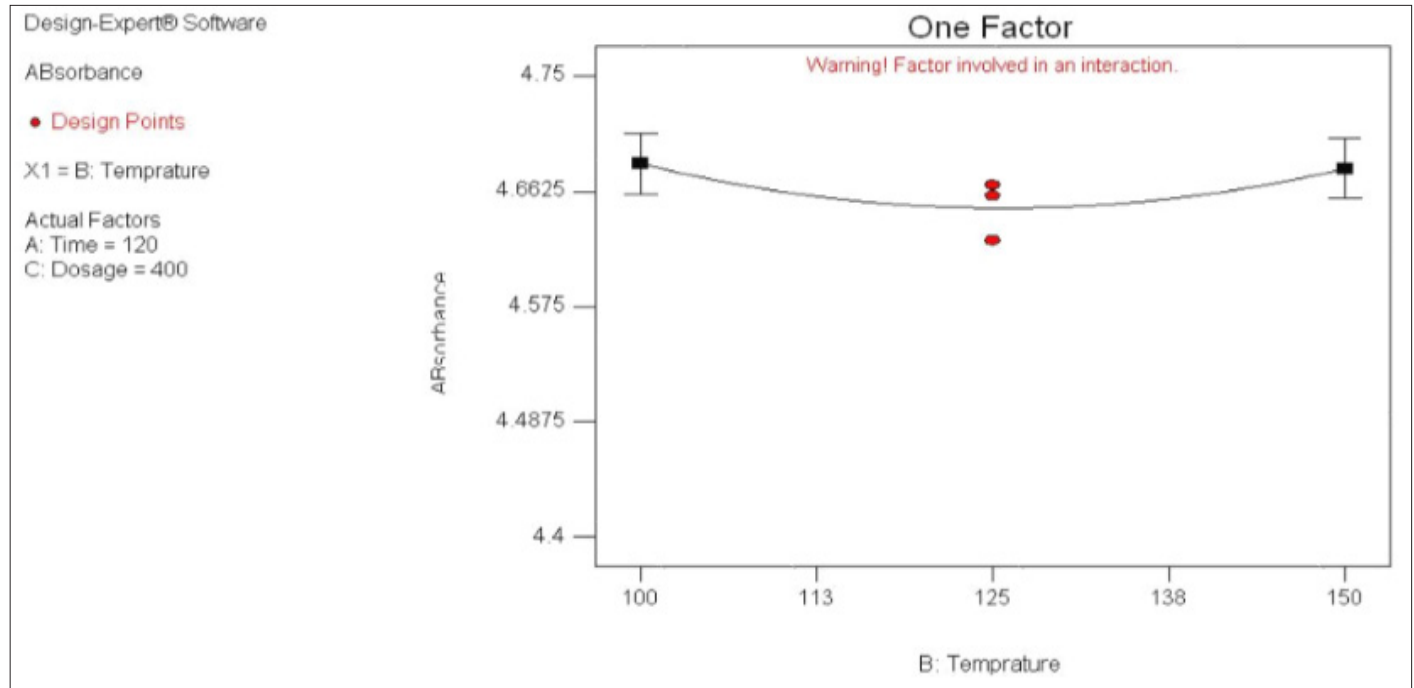

Fig. 11.The effect of reaction temperature on oil color by MCM-41

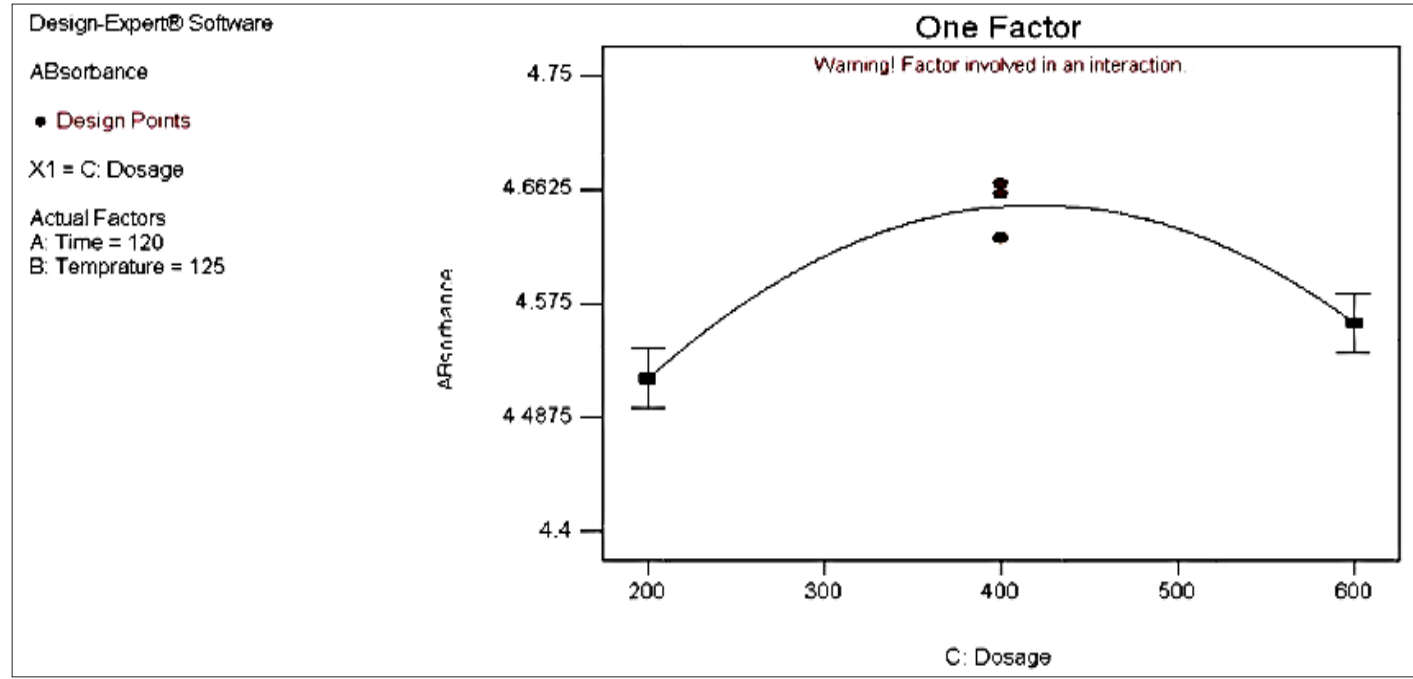

Fig. 12. The effect of dosage on oil color by MCM-41

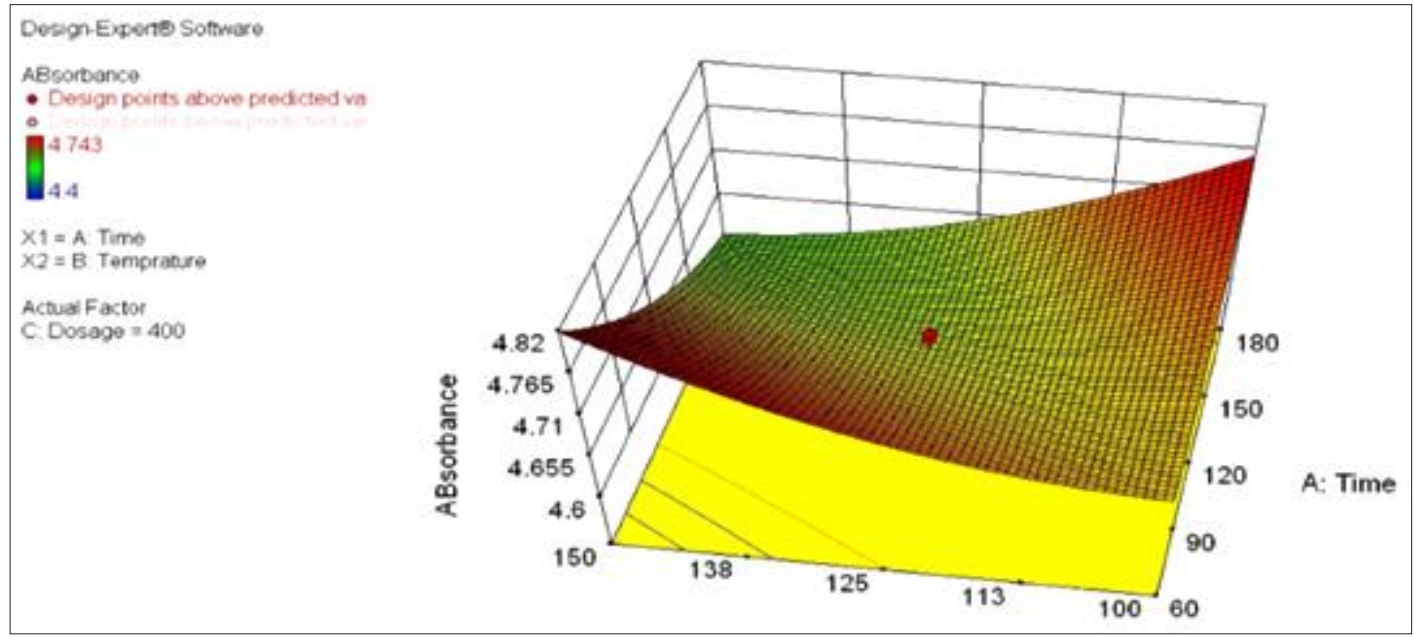

Fig. 13. The effect of interaction factors sodium metallic contact time and reaction temperature it on oil color by MCM-41 


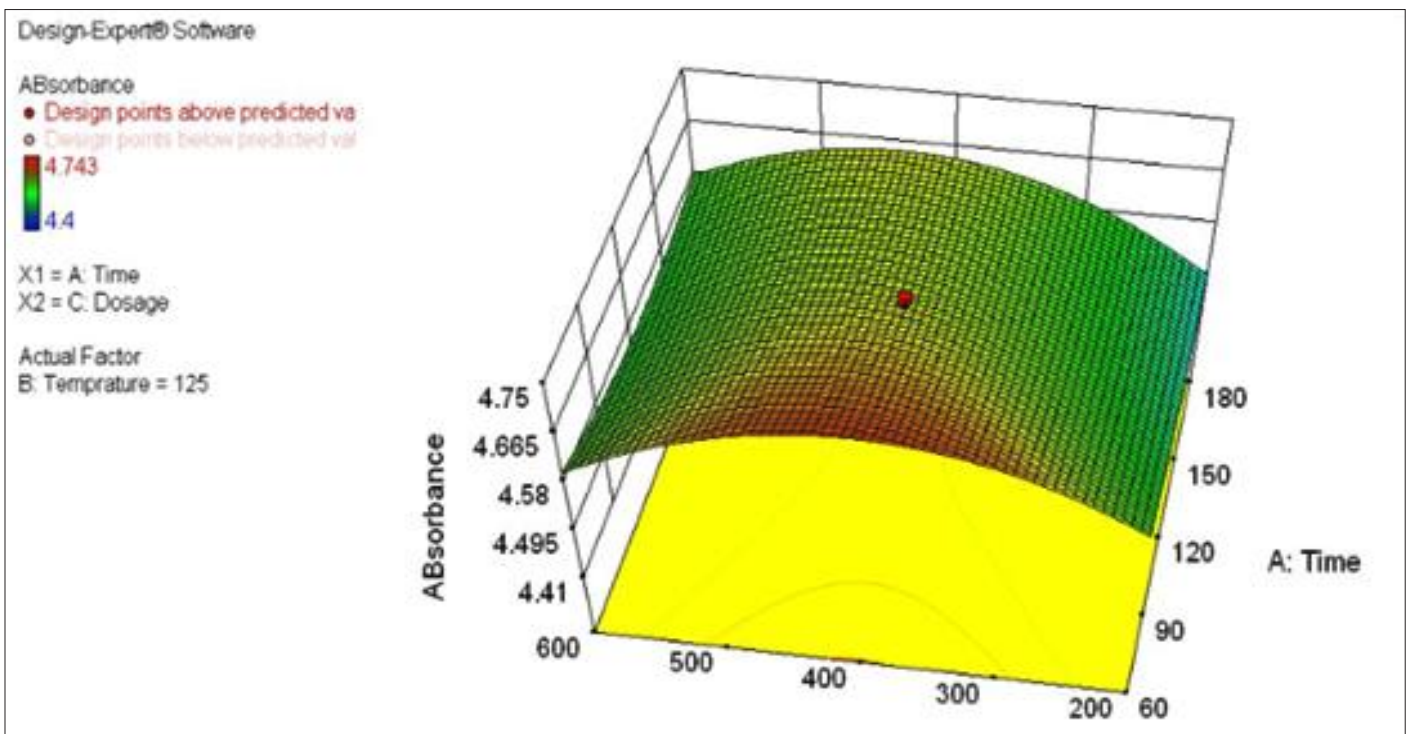

Fig. 14. The effect of interaction factors sodium metallic contact time and dosage(sodium to oil ratio) on color oil by MCM-41

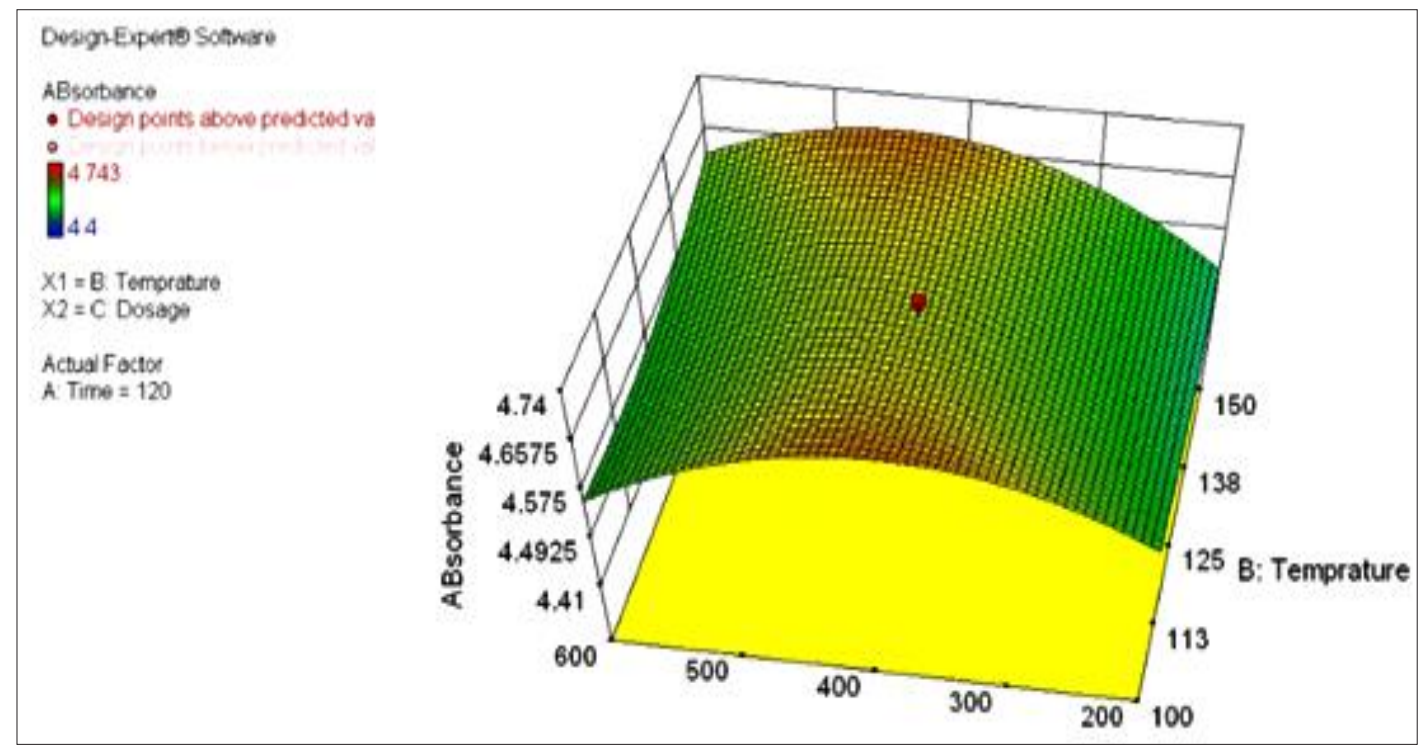

Fig. 15. The effect of interaction factors sodium metallic reaction temperature and dosage (sodium to oil ratio) on oil color by MCM-41

of $\mathrm{AB}, \mathrm{AC}$ and $\mathrm{BC}$. The curvature of the model was due to these terms. All main factors had interaction with each other.

\section{Conclusions}

In this research, we studied re-refining of used insulating oil by metallic sodium and mesoporous silicate containing aluminum. This method combines to adsorption and reduction of oxide species. The effective factors including time, temperature and dosage of sodium was statistically studied by ANOVA. The adsorption of mesoporous silica was also studied by this way. Based on proposed procedure, the modeling was carried out. 
Treating of oil with mesoporous silicate after using metallic sodium causes lower color of oil. Treating of oil by adsorption using MCM-41 followed by reduction with metallic sodium is somehow better in final quality of oil. This method is very effective for re-refining of isolation oil which is very important in the industry. Higher temperature results in better quality of product because of higher activity of sodium and oxidant species and also better diffusion of these species to the surface of active sites of sodium and mesoporous silica. Aluminosilica is more polar than silica because of its higher aluminum. But due to the higher acidic nature of the surface of aluminosilica, it is weaker adsorbent for the removal of acidic species from the oil.

\section{References}

[1] A. Hamada, E. Alzubaidy, M. Fayed, Used lubricating oil recycling using hydrocarbon solvents, J. Evnviron. Manage., 74 (2005) 153159.

[2] D. I. Osman, S. K. Attia, A. R.Taman, Recycling of used engine oil by different solvent, Egyptian J. Petrol., 27 (2018) 221-225.

[3] R. Abro, X. Chen, K. H. Harijan, Z.A. Dhakan, M. Ammar, A comparative study of recycling of used engine oil using extraction by composite solvent, single solvent, and acid treatment methods, Int. Sch. Res. Notices, 2013 ( 2013) 952589.

[4] J.A. Filho, L.G.M.M. Moura, A.C.S. Ramos, Liquid-liquid extraction and adsorption on solid surfaces applied to used lubricant oils recovery, Brazilian j. chem. Eng., 10 (2014) 687-697.

[5] T. Colclough, Role of additive and transition metalin lubricanting oil oxidation, Ind. Eng. Chem. Res., 26 (1987)1888-1895.

[6] K. Satish E. Klaus, L. Duda, Evaluation of liquid phase oxidation products of ester and minaral oil lubricants, Ind. Eng. Chem. Prod, Res. Dev., 23 (1984) 613-619.

[7] S. Bustamante, M. Manana, Dissolved gas analysis equipment for online monitoring of transformer oil: a review, Sensors, 19 (2019) 4057.

[8] Survey of currently available non-Incineration PCB destruction technologies, UNEP Chemical, 2000.

[9] R. Abu-Elella, M.E. Abu, R. Ossman, M. F. Abd-
Elfatah, Used motor oil treatment: turning waste oil into valuable products, Int. J. Chem. Biochem. Sci., 7 (2015) 57-67.

[10] MO. Aremu, DO. Araromi, OO. Gbolahan, Regeneration of used lubricating engine oil by solvent extraction process, Int. J. Energy Environ. Res., 3 (2015) 1-12.

[11] M.E. Emetere, Investigations on aerosols transport over micro-and macro-scale settings of west Africa, Environ. Eng. Res., 22 (2017) 75-86.

[12] H. Mensah-Brown, Re-refining and recycling of used lubricating oil: an option for foreign exchange and natural resource conservation in Ghana, J. Eng. Appl. Sci., 10 (2015) 797-801

[13] S.S. Lam, K.K. Liewa, A.A. Jusoh C.T. Chong F.N. Ani, H.A. Chase, Progress in waste oil to sustainable energy, with emphasis on pyrolysis techniques, Renew. Sust. Energ. Rev., 53 (2016) 741-753.

[14] T.E. Oladimeji, J.A. Sonibare, J. A. Omoleye, A.A. Adegbola, H. Okagbue, Data on the treatment of used lubricating oil from two different sources using solvent extraction and adsorption, Data in Brief, 19 (2018 ) 2240-2252.

[15] R. Maceiras, V. Alfonsín, F.J. Morales, Recycling of waste engine oil for diesel production, Waste Manage., 60 (2016) 351-356.

[16] S. Shiung Lam, R. Keey Liewa, A. Jusoh, C.T. Chong, F. Nasir Ani, H.A. Chase, Progress in waste oil to sustainable energy, with emphasis on pyrolysis techniques, Renew. Sust. Energ. Rev., 53 (2016)741-753.

[17] S. Salem, A. Salem, A. A. Babaei. Application of Iranian nano-porous Ca-bentonite for recovery of waste lubricant oil by distillation and adsorption techniques, J. Ind. Eng. Chem., 23 (2015)154-162.

[18] Standard Test Method for Acid and Base Number by color-Indicator Titratian-D947-04.

[19] J.M. Morales, A. Moragues, J.E.1. Haskouri, C. Guillem, J. Latorre, S. Murcia-Mascarós, A. Beltrán, D. Beltrán, P. Amorós, Low-Cost synthesis of bimodal mesoporous silica-based materials by pseudomorphic transformation, Chem. Plus chem., 80 (2015)1014-1028.

[20] R.J. With, R. Luque, V.L. Budarin, J.H. Clark, J.D. Macquarrie, Supported metal nanoparticles on porous materials nethods and applications, Chem. Soc. Rev., 38 (2009) 481-494. 
[21] Y.D. Chiang, H.Y. Lian, S.Y. Leo, S.G. Wang, Y. Yamauchi, Controlling particle size and structural properties of mesoporous silica nanoparticles using the Taguchi method, J. Phys. Chem. C, 115 (2011) 13158-65.

[22] P. Swan, R. Walker, B. Wopenka, J. Freeman, Absorption in interplanetary dust particles: evidence for indigenous hydrocarbons and a further link to comet halley, Meteoritics, 22 (1987) 510511.

[23] A. Zhang , Z. Li ,Y. Shen ,Y. Zhu, Effects of different Ti-doping methods on the structure of pure silica MCM-41 mesoporous materials, Appl. Surf. Sci., 254 (2008) 6298-304. 